\title{
Meeting Performance Goals by the Use of Experience Data
}

\author{
December 1, 1994 \\ Prepared by: \\ Michael W. Salmon \\ EQE Engineering Consultants \\ 18101 Von Karmañ Avenue, Suite 400 \\ Irvine, CA 92715 \\ Robert P. Kennedy \\ RPK Structural Mechanics Consulting \\ 18971 Villa Terrace \\ Yorba Linda, CA 92686
}

Prepared for:

Lawrence Livermore National Laboratory

Livermore, CA

and

U.S. Department Of Energy

Existing Facilities Project Steering Group and Technical Review Team 


\section{DISCLAIMER}

This document was prepared as an account of work sponsored by an agency of the United States Government. Neither the United States Government nor the University of California nor any of their employees, makes any warranty, express or implied, or assumes any legal liability or responsibility for the 2ccuracy, completeness, or usefulness of any information, apparatus, product, or process disclosed, or represents that its use would not infringe privately owned rights. Reference herein to any specific commercial products, process, or service by trade name, trademark, manufacturer, or otherwise, does not necessarily constitute or imply its endorsement, recommendation, or favoring by the United States Government or the University of California. The vieffsand opinions of authors expressed herein do not necessarily state or reflect those of the United States Government or the University of California, and shall not be used for advertising or product endorsement purposes.

This report has been reproduced directly from the best available copj.

Available to DOE and DOE contractors from the Office of Scientific and Technical Information P.O. Box 62, Oak Ridge, TN 37831

Prices available from (615) 576-8401, FTS 626-8401

Available to the public from the

National Technical Information Service

U.S. Department of Commerce

S285 Port Royal Rd,

Springfield, VA 22161 
December 1, 1994

\section{Acknowledgments}

The authors are grateful to Dr. John W. Reed and Mr. George A. Antaki for reviewing this report and for their numerous helpful suggestions. Dr. Reed's suggestion on the use of simulation techniques for obtaining the experience data factor for use with the SQUG Reference Spectrum is especially appreciated. 
Page

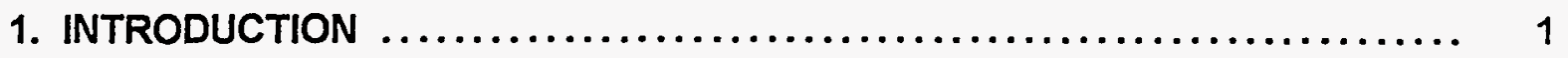

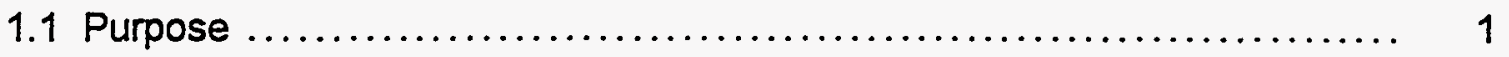

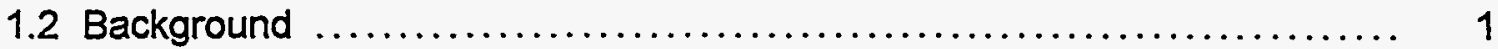

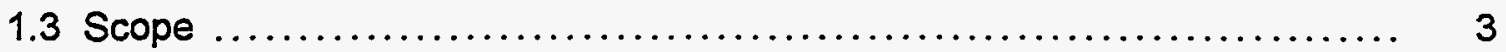

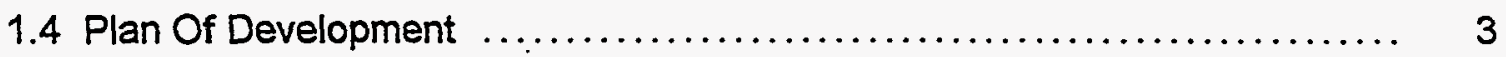

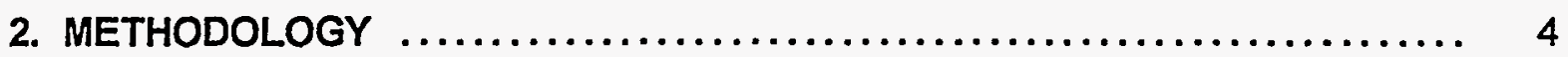

2.1 Performance Based Design Criteria ............................... 4

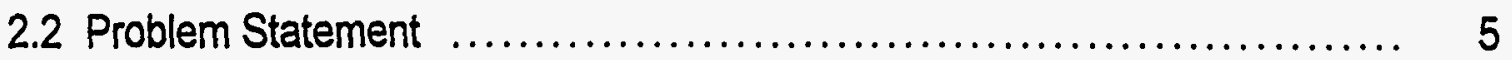

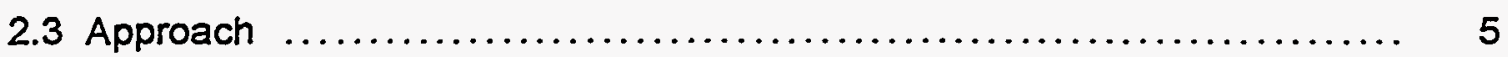

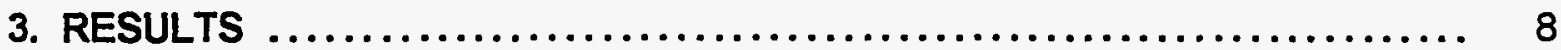

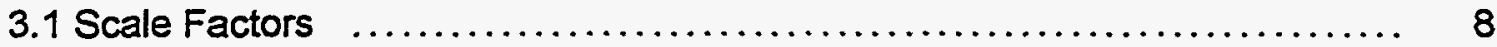

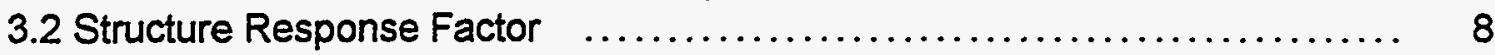

3.2.1 Performance Category 3 and Higher SSCs $\ldots \ldots \ldots \ldots \ldots \ldots \ldots . \quad 8$

3.2.2 Performance Category 2 and Lower SScs $\ldots \ldots \ldots \ldots \ldots \ldots \ldots . \quad 9$

3.3 Equipment Capacity Factor .................................. 10

3.3.1 Component Specific Qualification Test Reports (TRS) ............. 11

3.3.2 GERS ............................................ 11

3.3 .3 Relay - GERS ...................................... 12

3.3.4 Reference Spectrum ................................... 13

4. RECOMMENDED CRITERIA $\ldots \ldots \ldots \ldots \ldots \ldots \ldots \ldots \ldots \ldots \ldots \ldots \ldots \ldots \ldots \ldots \ldots \ldots \ldots, 17$

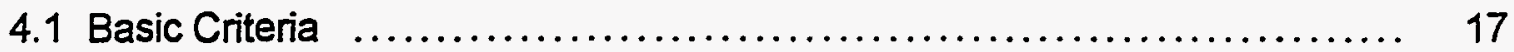

4.2 Relaxed Criteria ........................................... 18

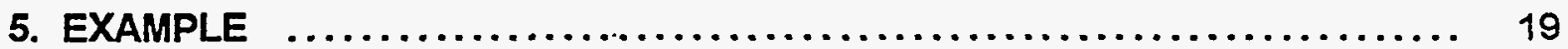

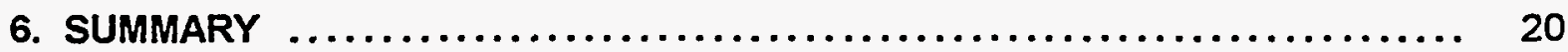

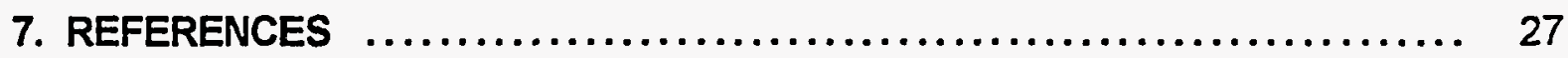




\section{TABLES}

Page

1. Performance Goals and Categories for SSCs $\ldots \ldots \ldots \ldots \ldots \ldots \ldots \ldots .21$

2. Scale Factors Required for Various Performance Categories ............. 21

3. Equipment Classes Represented in SQUG GIP [8] ................... 22

4. Summary of Capacity Factors, and Experience Data Factors for Use with Experience Data

\section{FIGURES}

Page

1. SQUG GIP [8] Bounding and Reference Spectra ..................... 24

2. Generic Equipment Ruggedness Spectra (GERS) for Various Equipment Classes.

3. Comparison of MCC GERS to Factored IRS 


\section{INTRODUCTION}

This paper was prepared for review by the DOE Steering Group and Technical Review Team responsible for establishing criteria for use with experience data in DOE facilities.

\subsection{PURPOSE}

The purpose of this paper is to present the results of research performed to date on quantifying the performance of structures, systems, and components (SSCs) whose seismic capacity is defined using experience data. Methodology is also presented.

Criteria are proposed for use with experience data approaches. The criteria are developed based on the performance goals contained in References 4 and 6 . The proper application of the criteria ensure that performance goals are achieved by SSCs evaluated using the methods contained in Generic Implementation Procedure (GIP) for Seismic Verification of Nuclear Power Plant Equipment [8]. Four general component classes are reviewed:

1. SSCs whose capacity is defined by GERS [1],

2. SSCs whose capacity is defined by Relay-GERS [2],

3. SSCs whose capacity is defined by component specific seismic qualification shake table tests performed in accordance with IEEE 344-1975 standards [3], or better, and,

4. SSCs whose seismic capacity is defined by the GIP Reference Spectrum.

\subsection{BACKGROUND}

DOE Order 5480.28 [4] requires that structures, systems and components be designed and constructed to withstand the effects of natural phenomena hazards (NPH). The target safety levels for SSCs subject to natural phenomena hazards are given in DOE Order 5480.28 in terms of performance goals. The performance goal is defined as the acceptable annual probability of failure.

For SSCs to be acceptable, it must be demonstrated that there is a sufficiently low probability of damage / failure of those SSCs consistent with established performance 
goals. These performance goals are shown in Table 1, and are a function of SSC classification. SSCs are classified in accordance with DOE Standard 1021-93 [5].

Performance goals are achieved in design by the use of NPH loads taken from probabilistic hazard assessments combined with response and evaluation methods that establish the necessary levels of conservatism for each SSC. For components qualified by test, performance goals are achieved by specifying a required response spectrum and test method with minimal acceptance standards. Reference 6 adapts both of these approaches to ensure that the appropriate performance goals are met for new installations. For existing SSCs, however, these approaches are generally not applicable.

The analyst can use a probabilistic approach to determine the performance goals achieved by existing SSCs. By this approach, the probability of unacceptable performance is obtained by a convolution of the seismic hazard and SSC fragility curves. This convolution can be expressed by either:

$\mathrm{P}_{F}=-\int_{0}^{\infty}\left(\frac{\mathrm{dH}_{(\mathrm{a})}}{\mathrm{da}}\right) \mathrm{P}_{\mathrm{Fla}} \mathrm{da}$

or

$\mathrm{P}_{F}=\int_{0}^{\infty} \mathrm{H}(\mathrm{a})\left(\frac{\mathrm{dP}_{\mathrm{Fla}}}{\mathrm{da}}\right) \mathrm{da}$

where $H(a)$ is the probabilistic seismic hazard curve which expresses annual probability of exceedance versus ground motion level "a", and $\mathrm{P}_{\mathrm{F} \mid \mathrm{a}}$ is the conditional probability of failure given the ground motion level "a" which is defined by the SSC fragility curve. This direct approach may always be used to obtain probability of failure for SSCs.

The criteria proposed in this paper provide the analyst with a deterministic approach that achieve the probability goals in References 4 and 6 . The criteria are consistent with the provisions of Reference 6 , and should be readily understood by design engineers who may be unfamiliar with probabilistic methods. The criteria are designed to be used with the SQUG approach presented in Generic Implementation (GIP) Procedure for Seismic Verification of Nuclear Power Plant Equipment [ 8].

The SQUG approach contained in Reference 8 was developed for use in verifying the seismic adequacy of existing SSCs in older nuclear plants. The Reference 8 methodology has been noted by the USNRC as "acceptable for verifying seismic adequacy 
of equipment in USI A-46 plants" [9]. The SQUG approach is based on seismic experience data. A simple set of screening rules, keyed to a generic bounding spectrum forms the basis of the approach. A generic experience-based response spectrum (i.e., the Reference Spectrum) defines the seismic capacity of components passing screening rules and inclusion caveats contained in Reference 8 . The SQUG approach ensures that components meeting the inclusion caveats and passing the screening rules contained in Reference 8 perform adequately up to seismic motion levels defined by the Reference Spectrum.

\subsection{SCOPE}

This report presents a straightforward approach that may be used to show the performance goals met by SSCs whose seismic capacity is verified using experience data. The methodology may be used with four different types of experience data:

1. GERS,

2. Relay-GERS;

3. Test Response Spectra, and

4. the SQUG Reference Spectrum.

The method presented is general enough so that it may be extended to other types of generic experience data approaches.

\subsection{PLAN OF DEVELOPMENT}

This report is presented in 6 main sections. Sections 1,2 and 3 are the body of the report and contain the introduction, the methodology and the results. The recommended criteria are presented in Section 4 . Section 5 presents an example. Section 6 is a summary. References are included. 


\section{METHODOLOGY}

The acceptance criteria to be developed for use with experience data approaches is conceptually simple. For a component to be acceptable, it must be shown that the component's seismic capacity exceeds the seismic demand by an appropriate margin. The difficulty in establishing the acceptance criteria is in quantifying that margin. The experience based methodologies presented in References 8 and 13 adapt the use of response spectra to define both component capacity and demand. This approach will be followed in this paper.

\subsection{PERFORMANCE BASED DESIGN CRITERIA}

The design and evaluation criteria contained in Reference 6 were developed to introduce controlled levels of conservatism. These levels of conservatism ensure that the performance goals given in Table 1 are achieved for SSCs in the appropriate performance categories. The amount of conservatism embedded in the analysis and design methods is discussed in Reference 12. The goal is that there should be less than about a $10 \%$ probability of unacceptable performance at input ground motion defined by a scale factor of 1.5SF times DBE:

$P(\mathrm{~A} \leq 1.5 S F \cdot D B E) \leq 10 \%$

Where $P\left(\mathbf{A} \leq a_{i}\right)$ represents the probability that the ground motion capacity of the SSC, $\boldsymbol{A}$ (a random variable), is less than the given ground motion $a_{i}$. SF is a scale factor developed specifically to achieve a performance goal for a specific performance category. The scale factors for each performance category are given in Table 2. The scale factors are required to achieve a reduction in the risk since the design basis earthquake is established at a higher annual frequency of occurrence than the acceptable annual probability of failure of the SSC. Reference 12 documents the basis for the scale factors listed in Table 2.

The total demand on the SSC is a combination of the scaled design basis earthquake loads with the best estimate concurrent non-seismic loads. Reference 6 allows the use of alternate acceptance criteria provided the criteria achieve less than about a $10 \%$ probability of unacceptable performance for the combination of the scaled DBE with the best-estimate concurrent non-seismic loads. 
The acceptance criteria for use with experience data methods adapt an alternate approach consistent with the guidance given in Reference 6 . The acceptance criteria may be formulated as:

$P_{F \mid a}\left(1.5 \cdot S F \cdot D_{s}+D_{N S}\right) \leq 10 \%$

Where:

$P_{F l a}$ is the probability of failure conditional on load case "a".

$D_{S}$ is the seismic induced demand from the design basis earthquake.

$D_{\text {NS }}$ is the demand due to the concurrent non-seismic loads.

SF is the scale factor for the appropriate performance category, see Table 2.

The seismic induced demand, $D_{\mathrm{s}}$ is established from peak ground motion at the appropriate annual hazard exceedance probability for the component performance category. The peak ground motion is established in accordance with Reference 6 . The acceptance criteria given by Equation 4 states that there is less than about a $10 \%$ probability of failure at the scaled design basis earthquake. The demand at the scaled design basis earthquake is a combination of the seismic loads and the concurrent non-seismic loads.

\subsection{PROBLEM STATEMENT}

The acceptance criteria is given in Equation 4. The seismic demand, $D_{s}$, is established following procedures as provided in References 6 and 11. The concurrent non seismic demand, $D_{\mathrm{NS}}$, is obtained following standard engineering mechanics principles.

The objective is defining the probability of failure as a function of ground motion, $\mathrm{P}_{\mathrm{F} \mid \mathrm{a}}$. This challenge becomes more difficult when capacity is defined from experience data. Once the probability of failure function is determined, criteria may be developed to show that performance" goals are met.

\subsection{APPROACH}

This issue has been addressed $[13,15,16,17]$ in support of probabilistic risk assessments and seismic margin assessments for many cases where the component capacity is defined by testing or by analysis. 
The probability of failure for structures, systems or components as a function of some seismic response parameter is defined the seismic fragility [17]. The double lognormal model is commonly used for fragility estimates [17]. The best estimate fragility may be expressed as a lognormal distribution with median value $\check{A}$, and lognormal standard deviation $\beta_{C}$ :

$f(a)=\Phi\left[\frac{\ln (a / \check{A})}{\beta_{C}}\right]$

Where:

$\Phi$ is the standard normal distribution function.

$f(a)$ is the failure frequency for a given level of ground motion, $a^{1}$.

$\check{A}$ is the median ground motion capacity.

$\beta_{C}$ is the total (composite) variability.

Equation 5 provides a single best estimate of the fragility curve which does not explicitly separate uncertainty from underlying randomness [17]. The total (composite) variability, $\beta_{C}$ is computed as the SRSS of the variability due to randomness, $\beta_{R}$, and that due to uncertainty, $\beta_{U}$.

The median ground motion capacity is often computed as the product of a number of factors of safety, which account for different levels of conservatism. The following formulation may be used for fragility evaluations where the capacity of a component is defined by experience data:

$\check{A}=\check{F}_{E C} \cdot \check{F}_{R S} \cdot F_{E D} \cdot a_{D B E}$

Where:

$\check{F}_{E C}$ is the median equipment capacity factor. $\check{F}_{E C}$ is the ratio of the ground motion level at which the equipment ceases to perform its intended function to the experience data capacity spectrum. The equipment capacity factor is a random variable.

$\check{F}_{R S}$ is the median structure response factor. $\check{F}_{R S}$ is the ratio of the reference instructure response spectrum at the component mounting location to the median

In this report, it is assumed that peak ground acceleration is used as the fragility ground motion parameter. In practice, any number of parameters may be used for the fragility function including spectral acceleration, peak velocity, average spectral acceleration, etc. 
centered in-structure response based on ground motion appropriate for the performance category of the component. The structure response factor is a random variable.

$F_{E D}$ is the experience data factor. $F_{E D}$ is the ratio of the experience data capacity spectrum to the reference in-structure response spectrum at the component mounting location. The experience data factor is a constant.

$a_{D B E}$ is the peak ground motion for the reference input. This is also a constant.

The equipment capacity factor, and the structure response factor will have variability due to both uncertainty and randomness. The composite uncertainty in the median ground motion capacity is calculated as the SRSS of the individual uncertainty parameters:

$\beta_{C}=\sqrt{\beta_{E C}^{2}+\beta_{R S}^{2}}$

The criteria in Equation 4 require a probability of failure of less than about $10 \%$ at a ground motion level equal to $1.5 \cdot S F \cdot a_{D B E}$. Setting "a" equal to $1.5 \cdot S F \cdot a_{D B E}$, and "f(a)" equal to 0.10 in Equation 5 and solving for the median ground motion capacity yields:

$\check{A}=1.5 \cdot S F \cdot a_{D B E} \cdot \exp \left(1.282 \cdot \beta_{C}\right)$

Equation 8 is another statement of the acceptance criteria given by Equation 4 in terms of median ground motion capacity, $\dot{A}$. Setting Equation 8 equal to Equation 6 , and solving for $F_{E D}$ gives:

$F_{E D}=1.5 \cdot S F \cdot\left(\frac{\exp \left(1.282 \cdot \beta_{C}\right)}{\check{F}_{R S} \cdot \check{F}_{E C}}\right)$

Equation 9 defines the experience data factor, or ratio of the experience-based capacity spectrum to the reference in-structure response spectrum at the component mounting location that is required in order to meet the performance goals contained in References 4 and 6 . The experience data factor forms the basis for the criteria which are presented later in this paper.

The experience data factor, $F_{E D}$, is a function of the conservatism in the experience data capacity spectrum and the in-structure-response spectrum. No additional uncertainty is associated with $F_{E D}$, since it is accounted for by $\check{F}_{R S}$ and $\check{F}_{E C} . F_{E D}$ represents the margin required between the experience data capacity spectrum and the reference in-structure response spectrum to meet the performance goals. The next section of this paper presents the derivation of the experience data factor for use with various data. 


\section{RESULTS}

The required experience data factor (Equation 9) is a function of the scale factor, $S F$, the median structure response factor, $\breve{F}_{R S}$, the median equipment capacity factor, $\breve{F}_{E C}$, and the composite uncertainty in both $\check{F}_{R S}$ and $\breve{F}_{E C}$. Each of these factors is discussed in more detail in the following sections.

\subsection{SCALE FACTORS}

The scale factors for use with equation 9 are presented in Table 2-4 and are required to ensure that the target performance goals are met. The derivation of the scale factors is presented in Reference 12. Briefly, the scale factors are derived to achieve a specified risk reduction over the annual exceedance probability for the design basis earthquake from parametric studies that examine typical seismic hazard curves and typical component fragility data.

\subsection{STRUCTURE RESPONSE FACTOR}

The structure response factor was defined as the ratio of the reference in-structure response spectrum at the component mounting location to the median centered in-structure response spectrum based on ground motion appropriate for the performance category of the component. The structure response factor, $\check{F}_{R S}$, is based on the response characteristics of the structure at the location of component support. The structure response factor is a function of variables used in generating the reference floor spectra for equipment design and evaluation. These variables include ground motion input, spectral shape (smoothing and broadening), damping, structure modeling, and soil structure interaction.

\subsubsection{Performance Category 3 and Higher SSCs}

Dynamic analysis are required for performance category 3 and higher SSCs by Reference 6 . Thus, floor spectra that were generated in accordance with Reference 6 will be available for many component evaluations. Reference 6 recommends the procedures given in ASCE 4-86 for use in generating in-structure response spectra. . Reference 12 reports a median structure response factor, $\breve{F}_{R S}$, of 1.28 with a lognormal standard deviation of 0.35 for use with in-structure response spectra generated in this manner. 
Rev. 2

December 1, 1994

When the reference in-structure response spectra are generated in accordance with Reference 6 at the ground motion appropriate for the performance category of the component, equation 9 may be rewritten as:

$F_{E D}=1.5 \cdot S F \cdot\left(\frac{\exp (1.282 \cdot \beta c)}{1.28 \cdot \dot{F}_{E C}}\right)$

In many cases, the reference in-structure response spectra may be based on ground motion other than that recommended in Reference 6 for the performance category of the component (original design basis, safety analysis, etc.). The structure response factor will need to be developed for use with Equation 9 for these cases. The structure response factor should account for differences between the median in-structure response spectra for the appropriate ground motion, and the reference in-structure response spectra used in the evaluation. Consult Reference 15 for the development of structure response factors.

\subsubsection{Performance Category 2 and Lower SSCs}

In-structure response spectra may need to be generated for use in evaluating Performance Category 2 and lower SSCs. The in-structure response spectra should be generated at the appropriate ground motion levels prescribed by Reference 6 at the performance categories of the equipment. In-structure response spectra are then developed using Reference 6 guidance. If this is done, then equation 10 may be used with a scale factor of 0.67 to develop the experience data factor.

Reference 6 endorses the use of Uniform Building Code type approaches for the design or evaluation of SSCs in performance category 2 and lower. By Reference 6, SSCs must be designed to resist a total lateral seismic force, $F_{p}$, of:

$F_{P}=Z I C_{P} W_{P}$

Where:

$W_{p}$ is the weight of the element or component

$C_{p}$ is a horizontal force factor given by Table 23-P of the. Uniform Building Code for rigid elements, or determined from the dynamic properties of the element and supporting structure for nonrigid elements (in the absence of detailed analysis, the value of $C_{p}$ for a nonrigid element should be taken as twice the value listed in Table 23-P but need not exceed. 2.0)

$Z$ is the peak ground acceleration from site-specific seismic hazard curves at specified annual exceedance probabilities. 
I is an importance factor equal to 1.25 for PC2 components, and equal to 1.0 for PC1 components

This approach was intended to be used for the evaluation of component anchorage and does not apply for use with experience data approaches. The UBC approach, given by equation 11, has implied ductility factors that effectively reduce the equivalent static load so that the use of this approach for comparison to spectral acceleration can be overly liberal. The use of experience data approaches for verifying the seismic adequacy of components requires a comparison of spectral acceleration capacity, given by the experience-based capacity spectra, to spectral acceleration demand, which must be estimated by floor response spectra.

\subsection{EQUIPMENT CAPACITY FACTOR}

The median equipment capacity factor, $\breve{F}_{E C}$, was defined as the ratio of the ground motion level at which the equipment ceases to perform its intended function to the experience data capacity spectrum. The equipment capacity factor, $\check{F}_{E C}$, is a function of the seismic ruggedness of the component, and the level at which the experience data capacity spectrum has been defined. The experience data capacity spectrum may be defined as either the SQUG Reference Spectrum [8], a Generic Ruggedness Spectrum [1, 2], or a Test Response Spectrum [3]. Experience data spectra may be developed for other equipment classes than are currently covered by Reference 8 .

This section presents the derivation of the median capacity factor, $\check{F}_{E C}$, and the experience data factor, $F_{E D}$. The experience data factor is derived for use with the four most common types of experience data. These include:

1. Component Specific Qualification Tests (TRS).

2. Generic Equipment Ruggedness Spectra (GERS).

3. Generic Equipment Ruggedness Spectra for Relays (Relay-GERS).

4. The SQUG Reference Spectrum

The resulting capacity factors, total variability, and the associated experience data factors are summarized in Table 4. The following sections present the derivation for each of those factors. 


\subsubsection{Component Specific Qualification Test Reports (TRS)}

An accurate estimate of the median capacity factor, $\check{F}_{E C}$, is impossible to make for equipment qualified by test. All that can be estimated from such a test is a lower bound of $\breve{F}_{E C}$. Standard test procedures use broader frequency content and longer duration input than is likely from an actual earthquake; furthermore, to pass the test, the equipment must function during and after the input. Therefore, $\check{F}_{E C}$ must substantially exceed unity. However, qualification tests do not typically address the possible differences between the seismic capacity of different equipment samples for a test run, because it's typical to test three or fewer samples of a component. Based upon Appendices $\mathrm{J}$ and $\mathrm{Q}$ of Reference 13 , Reference 12 reports that such qualification testing provides about a $90 \%$ to $98 \%$ confidence of acceptable equipment performance at the test response level, or failure probabilities for equipment that passed such a test from $2 \%$ to $10 \%$.

A median capacity factor of 1.40 for use with equipment qualified by test is reported in Reference 12. Reference 12 assumes that $\check{F}_{E C}$ is lognormally distributed with a lognormal standard deviation, $\beta_{\mathrm{EC}}$, of 0.20 based on a review of fragility results. Assuming that in-structure spectra were generated in accordance with Reference $6, \breve{F}_{R S}=1.28$, $\beta_{\mathrm{RS}}=0.35$ [12], the experience data factor for equipment qualified by test may be calculated from Equation 10 as:

$F_{E D}=1.5 \cdot S F \cdot\left(\frac{\exp (1.282 \beta c)}{\dot{F}_{R S} \dot{F}_{E C}}\right)=1.5 \cdot S F \cdot\left(\frac{\exp [1.282(0.40)]}{(1.28)(1.4)}\right) \cong 1.4 S F$

where,

$\beta_{C}=\sqrt{\beta_{E C}^{2}+\beta_{R S}^{2}}=\sqrt{0.20^{2}+0.35^{2}} \cong 0.40$

\subsubsection{GERS}

Generic Equipment Ruggedness Spectra (GERS) were developed for SQUG by ANCO [1]. GERS are similar to test response spectra in that only a lower bound estimate of the component's failure capacity can be made from the test data. The GERS capacity spectrum, similar to that shown in Figure 2 were based on a collection of test response spectra. For most qualification tests, however, failures are not recorded at the test response spectra. Thus, the GERS represent success data for many components subjected to broad frequency, long duration input motion. 
Appendix $Q$ of Reference 13 presents the median equipment capacity factor as a function of the uncertainty associated with the GERS:

$\check{F}_{E C}=\frac{\exp \left(2.33 \cdot \beta_{E C}\right)}{1.2}$

Where 1.2 is a test response spectra knockdown factor appropriate for use with Non Relays GERS.

Typical values of uncertainty, $\beta_{E C}$, for use with GERS range from 0.2 to 0.3 (Ref. 13). Reference 15 recommends the use of 0.25 for $\beta_{\mathrm{EC}}$. Therefore, using a $\beta_{\mathrm{EC}}$ of .25 in equation 12 results in a median equipment capacity factor for use with GERS of:

$\check{F}_{E C}=\frac{\exp (2.33 \cdot 0.25)}{1.2}=1.49$

Again, assuming that in-structure spectra were generated in accordance with Reference $6,, \breve{F}_{R S}=1.28, \beta_{\mathrm{RS}}=0.35$ [12], the experience data factor for equipment whose capacity is defined by GERS may be calculated from Equation 10 as:

$F_{E D}=1.5 \cdot S F \cdot\left(\frac{\exp (1.282 \beta C)}{\dot{F}_{R S} \dot{F}_{E C}}\right)=1.5 \cdot S F \cdot\left(\frac{\exp [1.282(0.43)]}{(1.28)(1.49)}\right) \cong 1.4 \cdot S F$

where,

$\beta_{C}=\sqrt{\beta_{E C}^{2}+\beta_{R S}^{2}}=\sqrt{0.25^{2}+0.35^{2}} \cong 0.43$

\subsubsection{Relay - GERS}

Generic Equipment Ruggedness Spectra (GERS) for relays are reported in Ref. 2. The GERS for relays are unique in that they were developed from seismic ruggedness tests, as opposed to qualification tests used for the non-relay GERS. The test programs used in development of relays-GERS were based on both broad-band and narrow-band input motions of varying levels to establish the relay chatter threshold level (fragility) and the chatter duration associated with input levels greater than the threshold level. Thus, the relays-GER' are essentially fragility tests, so that the capacity factor for relays-GERS may be expected to be less than that for non-relay GERS.

Appendix $Q$ of Ref. 13 and Reference 15 both report a median capacity factor of 1.07 for relays-GERS, with a corresponding $\beta_{\mathrm{EC}}$ of 0.20 . Using a median capacity factor of 1.07 and an $\check{F}_{R S}$ of 1.28 with a $\beta_{R S}$ of 0.35 in Equation 10, the experience data factor for use with relays GERS is calculated as: 


$$
F_{E D}=1.5 \cdot S F \cdot\left(\frac{\exp (1.282 \beta c)}{\check{F}_{R S} \dot{F}_{E C}}\right)=1.5 \cdot S F \cdot\left(\frac{\exp [1.282(0.40)]}{(1.28)(1.07)}\right) \cong 1.8 \cdot S F
$$

where,

$\beta_{C} \doteq \sqrt{\beta_{E C}^{2}+\beta_{R S}^{2}}=\sqrt{0.20^{2}+0.35^{2}} \cong 0.40$

Here again the assumption is made that in-structure spectra are generated in accordance with Reference 6.

\subsubsection{Reference Spectrum}

The Reference Spectrum was established based on survival data of similar components subjected to earthquakes at industrial facilities. The Reference Spectrum is shown in Figure 1. The Reference Spectrum is used for comparison to in-structure response spectra. Note that Reference 8 endorses the use of a "Bounding Spectrum" that is equal to the Reference Spectrum divided by a factor of 1.5. The 1.5 factor accounts for in-structure amplification, so that the Bounding Spectrum may be used to represent the ground motion capacity of components mounted in nuclear power plants at a height of 40 feet or less. DOE facilities are, in general, very different from nuclear power plant type structures so that the use of a 1.5 factor to account for structural amplification of ground motion may be unconservative, and is not allowed. Thus, the use of a Bounding Spectrum method does not apply to the evaluation of components mounted in DOE facilities.

In deriving a capacity factor for use with the Reference Spectrum several key assumptions need to be made, these assumptions are explained in the following paragraphs:

- There are effectively 50 independent samples in each component class that were subject to ground motions used in establishing the Reference Spectrum.

- There are essentially no incidences of failure for database components at the Reference Spectrum level, when the caveats in Reference 8 are met.

- The database equipment was subjected to a wide range of ground motions centered about the Reference Spectrum level. The input motion may be modeled as lognormally distributed with a median value of 1.0 times the Reference Spectrum level with a logarithmic standard deviation, $\beta_{i 1}$ of 0.30 . 
- The underlying failure distribution for the database equipment may be modeled with a lognormal distribution with a unknown median (to be determined) and a composite logarithmic standard deviation, $\beta_{c}$, of 0.45 .

Table 3 presents the number of components that were used in generating the Reference Spectrum [18]. Some of the components in Table 3 were judged by SSRAP to have high seismic capacity. These components included motor-generators, chillers, and engine generators. For the remainder of the components, Class 2 (Low Voltage Switchgear) has the fewest number of samples, about 70 . It is not known if all 70 samples are independent. Clearly, two identical cabinets mounted at the same location and subjected to the same input motion should not be counted as 2 independent samples. A lower bound estimate of the number of samples in each component class in earthquake experience data base may be assumed to be about 50 based on low voltage switchgear. Of the remaining component classes in Tabie 3, most have sizes of more than 100 .

The 20 general classes of equipment included in Reference 8 include roughly about 4000 items. Conservative estimates of the number of failures in the total inventory have placed the failures at 150 items [18]. Reference 18 concludes that of the instances of failure, "nearly all causes of damage would have been identified by a careful review process using the GIP." Thus, the assumption of no failures is justified when a thorough review is performed to narrow the sample set to include only those items passing the screening rules contained in Reference 8.

The input motion that "tested" the data base equipment was not available and had to be estimated [14]. The estimated input motion for each of the data base sites was derived from the closest free-field strong motion record available. It was judged by SSRAP [14] that the estimated input motions were "either a reasonable or a conservative representation (underestimation) of the horizontal free-field ground motion at the data base sites." Furthermore, the average of these estimated input motions could be used to establish the Reference Spectrum which provides a reasonable description of the ground motion level to which the earthquake experience-data demonstrate seismic ruggedness. Thus, the Reference Spectrum may be taken to be essentially median centered, but with some unknown uncertainty. It is unlikely that any equipment saw ground motion in excess of 2 times the Reference Spectrum level, or that equipment saw ground motion less than about 
$1 / 2$ times the Reference Spectrum level. For a lognormal distribution with logarithmic standard deviation of 0.30 less than $2 \%$ of the total number of samples fall outside of the range from $1 / 2$ to 2 times the central value. This range of motion is judged to be reasonable and conservative given the basis of the Reference Spectrum .

The equipment represented in the seismic experience data base consists of industrial grade equipment installed following standard procedures. The lognormal distribution has been used to describe the seismic capacity of industrial grade equipment $[13,15,16,17]$ and is widely accepted. Reference 12 notes that $\beta_{c}$ ranges from 0.3 to 0.6 in the extreme, and is typically between 0.4 to 0.5 . Therefore, an assumed composite standard deviation, $\beta_{c}$, of 0.45 is reasonable for a typical component.

The median equipment capacity factor, $\stackrel{\sim}{F}_{E C}$, of the component may be estimated using the preceding assumptions and a simulation technique. The median equipment capacity factor at an assumed confidence level $\mathrm{C}$ is solved for by the following equations::

$C=1-q_{N}$

$q_{N}=\prod_{i=1}^{N}\left\{1-\Phi\left[\frac{\ln \left(\frac{a_{i}}{\hat{F}_{C C a_{R}}}\right)}{\beta_{c}}\right]\right\}$

where:

$a_{R S}$ is the Reference Spectrum ground motion.

$a_{i}$ is a sample input motion value, the ground motion input, $a$, is assumed to be lognormally distributed with a median value of 1.0 times the Reference Spectrum level (i.e., $1.0 \times a_{R s}$ ), with a corresponding lognormal standard deviation, $\beta$, of 0.30 .

$q_{n}$ is the probability that all $N$ independent samples survive the ground motion values $a_{1}$.

$C$ is the assumed confidence level in the median equipment capacity

$\breve{F}_{E C}$ is the median equipment capacity factor.

$N$ is the number of independent samples

$\Phi$ is the cumulative normal distribution function.

A single variable latin hypercube simulation for the input motions that occurred at the database sites was performed for a sample set of size 50 . For an assumed confidence level of $95 \%$, the median equipment capacity factor, $\check{F}_{E C}$, was varied until equation 13 was 
December 1, 1994

satisfied. Equation 13 was satisfied when the median equipment capacity factor was equal to about 2.35. Thus, the experience data factor for use with the Reference Spectrum may be calculated as:

$F_{E D}=1.5 \cdot S F \cdot\left(\frac{\exp \left(1.282 \beta_{\epsilon}\right)}{\check{F}_{R S} \check{F}_{E C}}\right)=1.5 \cdot S F \cdot\left(\frac{\exp (1.282(0.45))}{1.28(2.35)}\right)=0.90 \cdot S F$

The selection of $95 \%$ confidence in the median equipment capacity factor is somewhat conservative, and a lower confidence limit may be warranted. However, because of the apparent robustness in the size of the survival set (Table 3), a conservative estimate of confidence may be made without drastic impact on the resulting $F_{E D}$ factor.

Because of uncertainties in the Reference Spectrum methodology, and its application to DOE facilities, this factor was increased to $1.0 \mathrm{SF}$. 


\section{RECOMMENDED CRITERIA}

\subsection{BASIC CRITERIA}

It was shown in Section 2.3, that the performance based criteria contained in Refs. 4 and 6 are met when the experience-based capacity spectrum defined as either the GERS, Relays-GERS, Test Response Spectrum, or Reference Spectrum exceeds the in-structure response spectrum generated in accordance with Reference 6 by a experience data factor, $F_{E D}$. The experience data factors were derived, and are presented in Table 4.

This approach forms the basis for the acceptance criteria and may be written as:

$C a p \geq F_{E D} \cdot I R S$

Where:

Cap: is the experience-based capacity spectrum defined by either the Reference Spectrum, GERS (non-relay), GERS (relay), or a component specific Test Response Spectrum.

$F_{E D}$ is the experience data factor. $F_{E D}$ is dependent upon the experience-based spectrum being used to define capacity. $F_{E D}$ is given in Table 4.

IRS: is some reference in-structure response spectrum. For most cases, IRS will be the median amplification in-structure response spectrum at the component's mounting location generated in accordance with Reference 6.

Equation 15 is the recommended criteria for use in evaluation of existing SSCs in DOE facilities. The criteria has the following additional requirements which must be met:

1. The experience-based capacity spectrum must bound the scaled plant seismic demand spectrum. The experience data factors given in Table 4 for use with Equation 15 are only correct if the in-structure response spectrum used for comparison to the experience-based capacity spectrum was generated in accordance with the procedures contained in Reference 6 , and was generated using ground motion appropriate for the performance category of the component. For other applications, the experience data factor must account for differences in both the ground motion and in the structure response. Equation 9 may be used to derive the appropriate experience data factor, $F_{E D}$ for use in these cases.

2. The equipment item must meet the inclusion rules and caveats as contained in Ref. 8. An assumption made in this methodology is that the caveats and inclusion rules contained in the GIP are met. If this is not the 
case, the experience data factors presented in Table 4 may be unconservative.

3. The component anchorage must be evaluated. The experience-based capacity spectrum defines a seismic capacity for component functionality following an earthquake. Structural failure modes, including anchorage still must be evaluated

4. Any potentially significant seismic systems interaction concerns that may adversely affect the component safe-shutdown function must be addressed.

If the experience-based capacity spectrum envelops the factored in-structure response spectrum for all frequencies above the lowest estimated fundamental frequency for the SSC being evaluated, and the above conditions are met, then the performance goals are met.

\subsection{RELAXED CRITERIA}

DOE-STD-1020-94 states that for facilities close to meeting the criteria, " some relief can be allowed by performing the evaluation using hazard exceedance probabilities twice the value recommended for the performance category of the SSC being considered" [6]. This doubling of the hazard exceedance probability is roughly equivalent to allowing a $20 \%$ margin of capacity over the demand. For existing SSCs, therefore, the verification method factor may be factored by 0.80 in order to provide relief for existing SSCs close to meeting the criteria.

Table 4 presents the experience data factors for four general types of experience-based capacity spectra. It is recommended that the full $F_{E D}$ given in Table 4 be used for the initial evaluation of existing SSCs. For SSCs that are close to meeting the criteria, the demand spectra may be reduced by a factor of 0.8 , as shown in Table 4 . It must be emphasized that the 0.80 factor can only be used with in-structure demand that was derived from ground motion specified at the appropriate hazard annual exceedance probability. Relief has already been taken if the in-structure demand was derived from ground motion at twice the recommended hazard annual exceedance probability, and the 0.80 factor cannot be used. 


\section{EXAMPLE}

Consider a motor control center (mcc) that is well anchored in a DOE facility. The ability of this MCC to function following the design basis earthquake is desired. The motor control center is classified as PC-4 in accordance with DOE-STD-1021-93. In-structure response spectra have been developed at $5 \%$ damping using the methods outlined in DOE-STD-1020-94. The response spectra follow the shape of NUREG CR/0098, and have a peak ground acceleration of $0.30 \mathrm{~g}$. The peak ground acceleration was obtained from a mean hazard curve at a annual probability of exceedance of $1 \times 10^{-4}$ (Performance Category 4). The component was walked down in accordance with the procedures contained in the GIP, and was found to meet both the inclusion rules and caveats for motor control centers (equipment class 1) as specified for GERS acceptability in Ref. 8, appendix B. Also, no potential seismic interaction concerns in the vicinity of the MCC where found.

The GERS will be used as the experience-based capacity spectrum in this example. The experience data factor for GERS is 1.4xSF (Table 4). This is used to scale up the in-structure response spectra for comparison to the GERS. A seismic scale factor of 1.25 is appropriate for PC4. The total factor for the IRS is then 1.75. This comparison is shown in Figure 3.

Note that the GERS shown in Figure 3 exceed the factored IRS over all frequency ranges of interest; thus, the performance goals appropriate for PC4 are ensured.

This component was compared to a NUREG CR/0098 ground spectra, which is typical of in-structure spectra for components mounted at or below basemat. The margin in the experience-based capacity spectrum shown by the GERS to the factored required response spectra may be needed to verify the seismic adequacy of components that are mounted high in structures. 


\section{SUMMARY}

DOE Order 5480.28 requires that all existing structures, systems, and components be evaluated for the effects of Natural Phenomena Hazards. The order endorses the graded approach outlined in DOE-STD-1020-94 in which structures, systems, and components are classified into one of four performance categories. Design and evaluation guidelines are contained in DOE-STD-1020-94 for each performance category. A probabilistic performance goal is associated with each performance category. The performance goal is the acceptable annual probability of failure.

The USNRC has adapted the Generic Implementation Procedure (GIP) as an acceptable methodology for resolution of USI A-46. The GIP contains generic experience-based capacity spectra for various equipment classes. These capacity spectra were developed from either real earthquake response spectra, or from a collection of test response spectra. The GIP methodology "is sufficiently rigorous to provide a level of safety comparable to that achieved by the current requirements applicable to nuclear power plants for verifying the seismic adequacy of equipment" [8]; however, the methodology of the GIP is not based on performance goals.

Criteria are proposed in this paper by which the experience data based methodology contained in the GIP can be used to verify the seismic adequacy of SSCs in DOE facilities, and meet the performance based criteria of DOE-STD-1020-94 and DOE Order 5480.28. The proposed approach adapts the methodology contained in the GIP with one addition. The capacity spectrum defined by either relay GERS, non-relay GERS, Qualification Test Response Spectra (TRS), or by the Reference Spectrum is compared to a scaled in-structure response spectrum (IRS). The scale factors used to increase the in-structure response spectrum are called "experience data" factors, and are a function of the experience data.being used to define capacity. Experience data factors were given for use with the Reference Spectra, Test Response Spectra, relay-GERS, and non-relay GERS. An example problem was provided. 
Table 1

Performance Goals and Categories for SSCs

\begin{tabular}{|c|l|c|}
\hline $\begin{array}{c}\text { Performance } \\
\text { Category }\end{array}$ & Description of Performance Required & $\begin{array}{c}\text { Seismic } \\
\text { Performance Goal }\end{array}$ \\
\hline PC0 & No Consideration & N/A \\
\hline PC1 & Prevent Structural Damage or Collapse & $1 \times 10-3$ \\
\hline PC2 & Maintain Essential Functions & $5 \times 10-4$ \\
\hline PC3 & Confinement of Hazardous Materials & $1 \times 10-4$ \\
\hline PC4 & Confinement of Hazardous Materials & $1 \times 10-5$ \\
\hline
\end{tabular}

Table 2

Scale Factors Required for Various Performance Categories

\begin{tabular}{|c|c|}
\hline Performance Category & Seismic Scale Factor, SF \\
\hline 1 & 0.67 \\
\hline 2 & 0.67 \\
\hline 3 & 1.00 \\
\hline 4 & 1.25 \\
\hline
\end{tabular}


Table 3

Equipment Classes Represented by SQUG GIP [8]

\begin{tabular}{|c|l|c|c|c|}
\hline $\begin{array}{c}\text { Class } \\
\text { Number }\end{array}$ & General Description & Number of Samples & $\begin{array}{c}\text { Number of } \\
\text { Sites }\end{array}$ & $\begin{array}{c}\text { Number of } \\
\text { Earthquake } \\
\text { s }\end{array}$ \\
\hline 1 & Motor Control Centers & 160 & 35 & 16 \\
\hline 2 & Low Voltage Switchgear & 70 & 22 & 12 \\
\hline 3 & Medium Voltage Switchgear & 75 & 30 & 13 \\
\hline 4 & Transformers & 85 & 32 & 12 \\
\hline 5 & Horizontal Pumps & 280 & 35 & 12 \\
\hline 6 & Vertical Pumps & 220 & 29 & 9 \\
\hline 7 & Fluid Operated Valves & 575 & 25 & 13 \\
\hline 8 & Motor Operated Valves & 300 & 16 & 9 \\
\hline 9 & Fans & $200-300$ & 24 & 16 \\
\hline 10 & Air Handlers & 90 & 15 & 9 \\
\hline 11 & Chillers & 30 & 10 & 4 \\
\hline 12 & Air Compressors & 125 & 30 & 11 \\
\hline 13 & Motor-Generators & 25 & 16 & 8 \\
\hline 14 & Distribution Panels & 100 & 25 & 12 \\
\hline 15 & Batteries and Racks & 120 & 45 & 15 \\
\hline 16 & Battery Chargers and Inverters & 90 & 36 & 14 \\
\hline 17 & Engine-Generators & 60 & 22 & 9 \\
\hline 18 & Instruments on Racks & 70 racks, 200 & 20 & 11 \\
\hline 19 & Temperature Sensors & 100 & 20 & 9 \\
\hline 20 & I/C Panels and Cabinets & $100^{1}$ & 20 & 9 \\
\hline 1 & Lower Bound Estimate & & & \\
\hline
\end{tabular}


Rev. 2

Table 4

Summary of Capacity Factors, and

Experience Data Factors for-Use With Experience Data

\begin{tabular}{|l|c|c|c|c|}
\hline $\begin{array}{c}\text { Spectrum Used to Define } \\
\text { Capacity }\end{array}$ & $F_{E C}$ & $\beta_{C}$ & $F_{E D}$ & $0.80 \times F_{E D}$ \\
\hline Qualification Test & 1.4 & 0.4 & $1.4 \times S F$ & $1.1 \times S F$ \\
\hline GERS (non-relay) & 1.49 & 0.43 & $1.4 \times S F$ & $1.1 \times S F$ \\
\hline GERS (relay) & 1.07 & 0.4 & $1.8 \times S F$ & $1.4 \times S F$ \\
\hline Reference Spectrum & 2.35 & 0.45 & $1.0 \times S F$ & $0.8 \times S F$ \\
\hline
\end{tabular}


Rev. 2

December 1, 1994

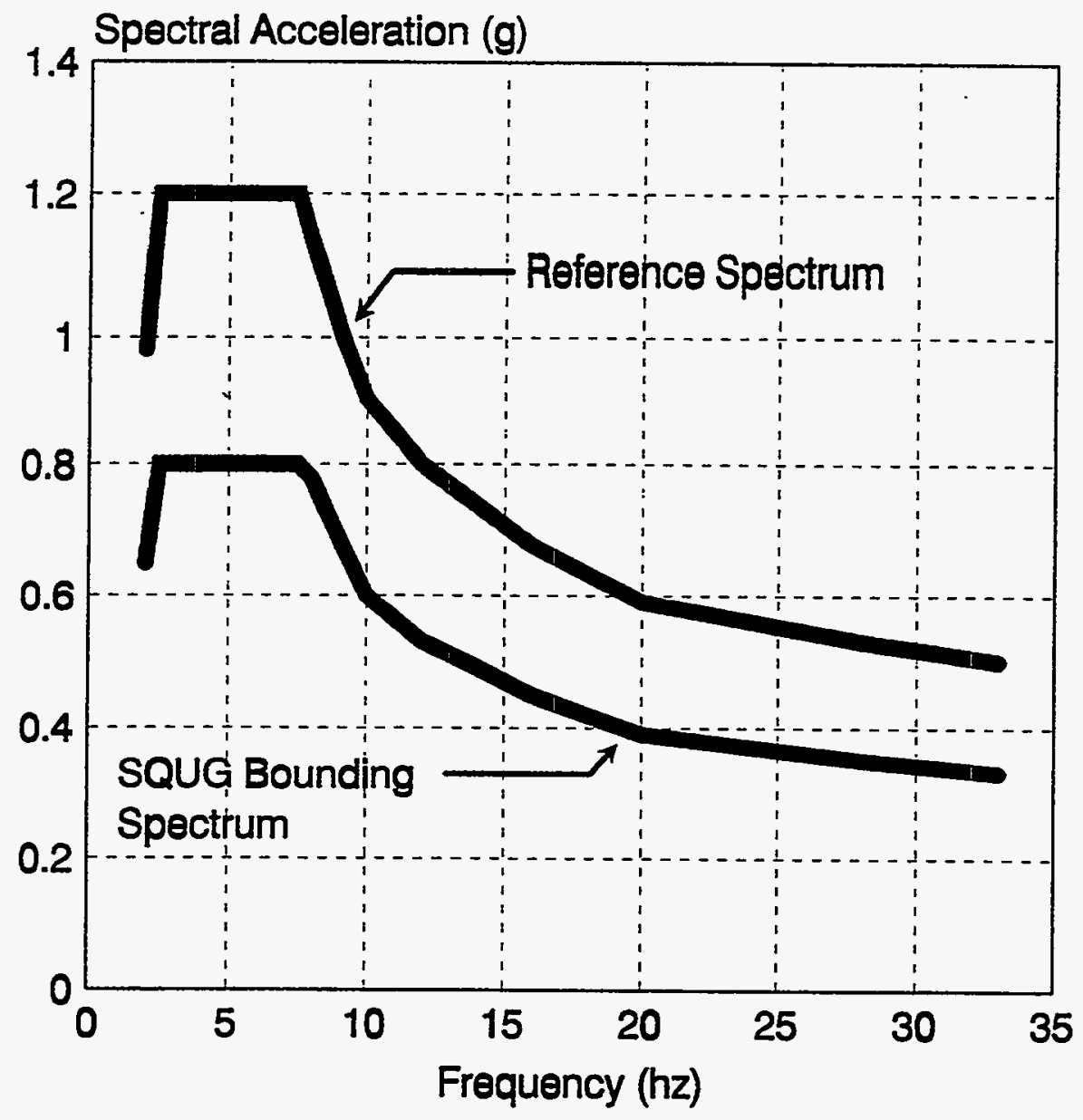

Figure 1

SQUG GIP [8] Bounding and Reference Spectra 


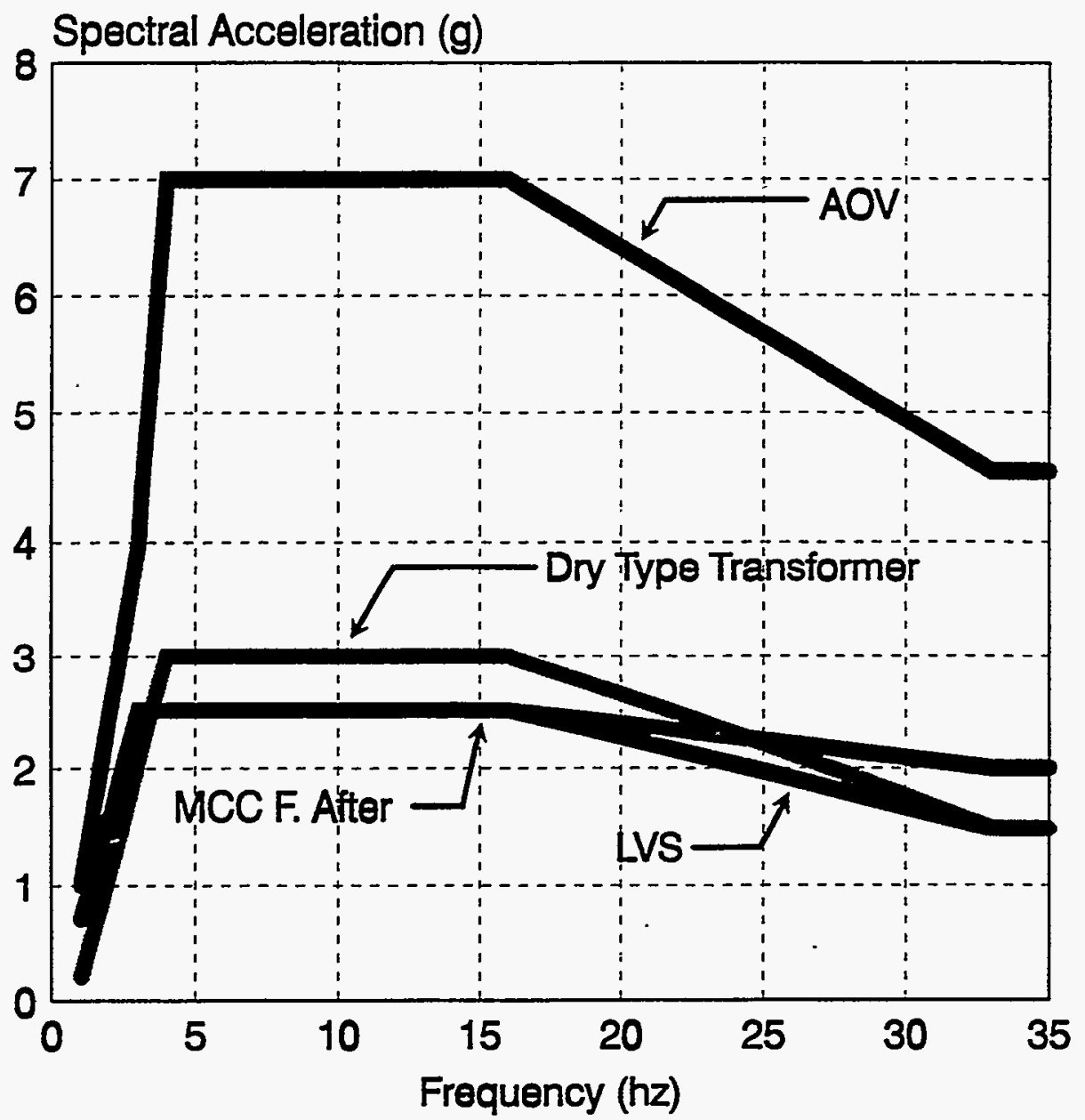

Figure 2

Generic Equipment Ruggedness Spectra (GERS)

for Various Equipment Classes. 
Rev. 2

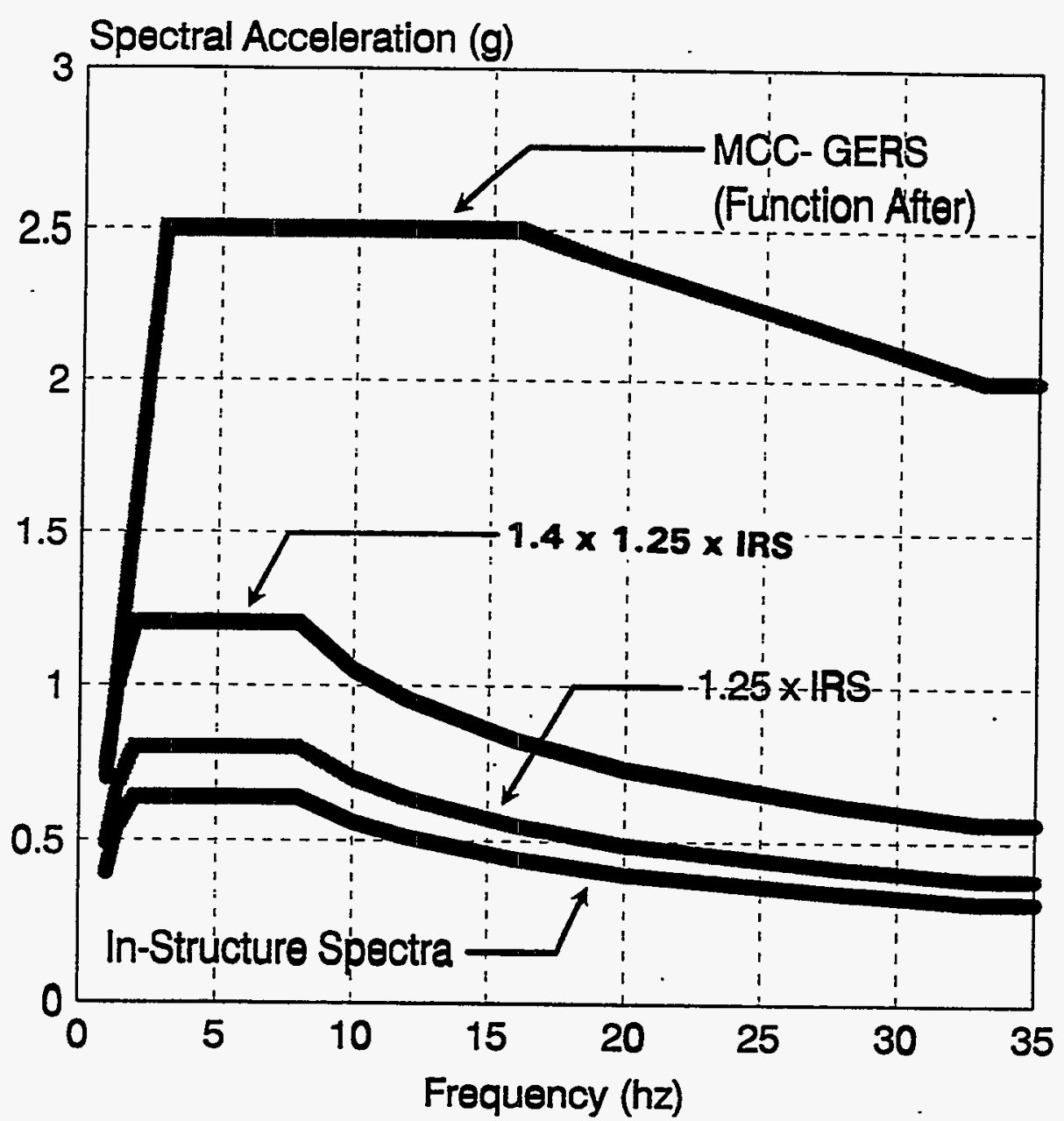

Figure 3

Comparison of MCC GERS to Factored IRS 


\section{REFERENCES}

1. Anco Engineers, "Generic Seismic Ruggedness of Power Plant Equipment (Revision 1)," EPRI NP-5223-SL, Rev. -5223-SL, Rev. 1, Electric Power Research Institute, Palo Alto, CA, August, 1991.

2. Anco Engineers, "Seismic Ruggedness of Relays," EPRI NP-7147-SL, Final Report, Electric Power Research Institute, Palo Alto, CA, August, 1991

3. The Institute of Electrical and Electronics Engineers, Inc., "IEEE Recommended Practices for Seismic Qualification of Class 1E Equipment for Nuclear Power Generating Stations," IEEE Std 344-1975, New York, New York, 1975.

4. U.S. Department of Energy, "Natural Phenomena Hazards Mitigation," DOE Order 5480.28, Washington, D.C., January 15, 1993.

5. U.S. Department of Energy, "DOE STANDARD, Natural Phenomena Hazards Performance Categorization Criteria for Structures, Systems, and Components," DOE-STD-1021-93, Washington, D.C., July, 1993.

6. U.S. Department of Energy, "DOE STANDARD, Natural Phenomena Hazards Design and Evaluation Criteria for Department of Energy Facilities," DOE-STD-1020-94, Washington, D.C., April, 1994.

7. Chang, T.Y., "Seismic Qualification of Equipment in Operating Nuclear Power Plants, Unresolved Safety Issue A-46," NUREG-1030, U.S. Nuclear Regulatory Commission, Office of Nuclear Reactor Regulation, August, 1986.

8. SQUG, "Generic Implementation Procedure (GIP) for Seismic Verification of Nuclear Plant Equipment," Available from USNRC Public Document Room (920918-MS), Washington, D.C., February, 1992.

9. United States Nuclear Regulatory Commission, "Supplemental Safety Evaluation Report No. 2 on Seismic Qualification Utility Group's Generic Implementation Procedure, Revision'2, Corrected February 14, 1992 for Implementation of GL 87-02 (USI A-46), Verification of Seismic Adequacy of Equipment in Older Operating Nuclear Plants," Office of Nuclear Reactor Regulation, May 22, 1992.

10. Kennedy, R.P., et. al., "Design and Evaluation Guidelines for Department of Energy Facilities Subjected to Natural Phenomena Hazards," UCRL-15910, U.S. Department of Energy, Lawrence Livermore National Laboratory, Livermore, CA, June, 1990. 
11. American Society of Civil Engineers, "ASCE Standard 4-86, Seismic Analysis of Safety-Related Nuclear Structures and Commentary on Standard for Seismic Analysis of Safety Related nuclear Structures," Working Group on Seismic Analysis of Safety Related Nuclear Structures, ASCE, New York, New York, September, 1986.

12. Kennedy, R.P, and Short, S.A., "Basis for Seismic Provisions of DOE-STD-1020, " UCRL-CR-111478, Revision 1, Lawrence Livermore National Laboratory, Livermore, CA, April, 1994.

13. Electric Power Research Institute, "A Methodology for Assessment of Nuclear Power Plant Seismic Margin," EPRI-NP-6041-SL, Revision 1, Palo Alto, CA, August, 1991.

14. Senior Seismic Review and Advisory Panel (SSRAP), "Use of Seismic Experience and Test Data to Show Ruggedness of Equipment in Nuclear Power Plants," Seismic Qualification Utility Group, June 1992.

15. Reed, J.W., and Kennedy, R.P., "Methodology for Developing Seismic Fragilities," EPRI TR-103959, Prepared for Electric Power Research Institute, Nuclear Seismic Risk Program, Palo Alto, CA 94304, June, 1994.

16. Kennedy, R.P., and Reed, J.W., "Post-Symposium Seminar on Fragility Evaluation for Probabilistic Risk Assessments for Nuclear Power Plants," Orlando, FL, December 14-18, 1992, Sponsored by North Carolina State University.

17. Kennedy, R.P, and Ravindra, M.K., "Seismic Fragilities for Nuclear Power Plant Seismic Risk Studies," Nuclear Engineering and Design, Volume 79, No. 1, May (I) 1984.

18. Seismic Qualification Utilities Group, "Summary of the Seismic Adequacy of Twenty Classes of Equipment Required for the Safe Shutdown of Nuclear Plants, a Supplement," Publication Pending SQUG approval, January, 1994.

19. Salmon, M.W., and Kennedy, R.P., "Meeting Performance Goals by the Use of Experience Data," Presented at the Fourth DOE Natural Phenomena Hazards Conference, August, 1993. 